\title{
Three-dimensional fluid-thermal-structure multiphysics interaction simulation model of aluminium extrusion process
}

\author{
Maher A. R. Sadiq Al-Baghdadi, Muhannad Al-Waily \\ Department of Mechanical Engineering, Faculty of Engineering, University of Kufa, Najaf, Iraq \\ Mobile: +9647719898955; Phone: +96433340952; Fax: +96433340951
}

ABSTRACT - Three dimensional fluid-thermal-structure multiphysics interaction simulation model of aluminium extrusion process has been simulated and presented in this paper. This multiphysics complex geometrical engineering process is simulated effectively using computational fluid dynamics (CFD) simulation with very high accuracy, where the aluminium material is treated as a fluid that has a very high viscosity which depends on temperature and velocity. When aluminium moving, the inner friction will work as a heat source, therefore the model of the heat transfer is completely coupled together with those governing model of the fluid dynamics. Material properties come into a viscosity function that can be related to the flow stress locally depending on forming velocity and temperature. In addition, the stresses distribution in the die that introduces due to the fluid pressure and the thermal loads has been modelled by fully coupled the simulation model with the structural mechanic's analysis. Fully three-dimensional results during the process of the temperature distribution, velocity profile, von Mises stress distribution, total displacement and deflection distribution, equivalent volumetric strain distribution, and pressure distribution are presented and analysed with a focus on the fundamental understanding. The model is shown to be able to provide a computer-aided design tool for optimize this complex engineering process by improving productivity and reducing scrap.
ARTICLE HISTORY

Received: $28^{\text {th }}$ Apr 2020

Revised: $18^{\text {th }}$ Feb 2021

Accepted: 06 $6^{\text {th }}$ Mar 2021

\section{KEYWORDS}

Aluminium extrusion;

CFD;

multiphysics;

fluid-thermal-structure

interaction;

three-dimensional model;

stress.

\section{INTRODUCTION}

Aluminium extrusion is a compressive deformation process in which a billet (workpiece) is pressed through an orifice (slot) or die opening in the shape of the required cross-section. The workpiece deforms plastically and starts following under indirect compressive load through the die opening. Generally, the extrusion process required a high forming force. The great hydrostatic stress in extrusion helps to enhance the material ductility. The workpiece is preheated to a temperature between 400 and 500 degrees centigrade before entering the container to achieve its plastic deformation [1].

Kjell [1] used the implicit finite element simulations to model the process of the hot extrusion of aluminium alloys (6082) of one hollow and two solid profile. The extrusion pressure, temperature distribution and the effect of die design for two dies were predicted. The effect of varying process conditions on the microstructure was performed experimentally. They showed good agreement for the predicted microstructures when using associated models with experimental measurements. Also, the predicted cracking showed a good correlation with experimental results.

Kulczyk et al. [2] studied the influence of the extrusion process and severe deformation induced effects in one pass via hydrostatic extrusion process on the mechanical properties of aluminium -silicon alloy, fine aluminium, copper, and silver wire. They showed that the fine aluminium and silver wires that processed through hydrostatic extrusion have a best properties based on mechanical and high surface feature.

Bakhtiani et al. [3] simulated the aluminium die extrusion process using a finite element model incorporating in Archards wear model and then validated experimentally. The simulated model can be used to expect the lifetime of the dies, and also to calculate and optimize the accurate quantity of thickness required for the coating to increase die lifecycle. They showed that when they coated the die, the die will become have a higher resistance to wear and temperature than uncoated die.

Bressan et al. [4] studied and analysed the hot extrusion process for aluminium via computational fluid dynamics and predicted the velocity fields and the stress of aluminium alloy 6351 flow in the axisymmetric extrusion process in the condition of steady-state. They suggested that their model can be applied in the solution of metal forming processes with good accuracy.

Chahare and Inamdar [5] performed twenty-seven experiments using Taguchi design of experiments by considering the combination of three factors of the process (i.e. the speed of the ram, the temperature variation of the billet pre-heating, and the temperature variation of the container) at three levels to find the feature angularity for instance response parameter for a two tracks top extruded profile. Taguchi's signal to noise ratio was used to find the optimum process parameters for feature angularity of a two tracks top profile that extruded by direct hot extrusion of 6063 aluminium alloy. They showed 
that the optimum level of parameters is ram speed at $6 \mathrm{~mm} / \mathrm{sec}$, billet preheating temperature and container temperature at $500 \mathrm{oC}$ and $400 \mathrm{oC}$ respectively.

Lou et al. [6] predicted the pressure field and the velocity field of the aluminium alloy profile extrusion process, using the computational fluid dynamics based on Euler mesh to simulate a steady or transient three-dimensional model of aluminium alloy profile of the hot extrusion process. According to their overall assessments in material flow, computation efficiency, the distributions of the physical field variables, and extrudate's shape, they concluded that using the finite volume method in the simulation was much more suitable to aluminium alloy profile extrusion process.

Bastani et al. [7] studied the effects of the speed of the ram, the distribution of the initial temperature in the billet and the cooling rate of the container on the flow balance and temperature growth of the extruded sections in the aluminium extrusion process using the transient finite-element simulation model. They showed that to decrease variations in the complete process of the extrusion, it is very essential to attention on governing flow as well as temperature development in the die and the container. Their results indicated that the early lateral temperature gradient has an important effect on the flow balance and therefore on the shape of the section produced. The influence of such an early lateral temperature gradient had better, therefore, be carefully controlled, considered, and monitored at what time efforts are made to achieve a reduction in the variations in the extrusion process.

Zhao et al. [8] obtained the distributions of the rate of strain, temperature, stress, and aluminium flow velocity in the extrusion process using the arbitrary Lagrangian-Eulerian adaptive re-meshing technology and the HyperXtrude software of transient finite element simulations, and then validated experimentally. They indicated that this method of simulation may well predict the flaws in the actual aluminium extrusion process.

In this work, a three-dimensional fluid-thermal-structure multiphysics interaction simulation model has been developed to simulate the process of the aluminum extrusion to reduce the variations in this important industrial process. The vision and comprehension added from this research work will be used to progress the die optimizes, die design, die manufacturing, and die life.

\section{COMPUTATIONAL MODEL}

Extrusion is a forming process that causes huge strains in the aluminium to be able to flow through the die, thus getting the wanted shape (Figure 1). The billet in the extrusion process is hard-pressed by utilizing the ram through the orifice of the die and its magnitude is constantly decreasing. To simulate this complex geometrical process with reasonable dimensions, the present simulation model considers only a quarter of the original geometry (Figure 2).

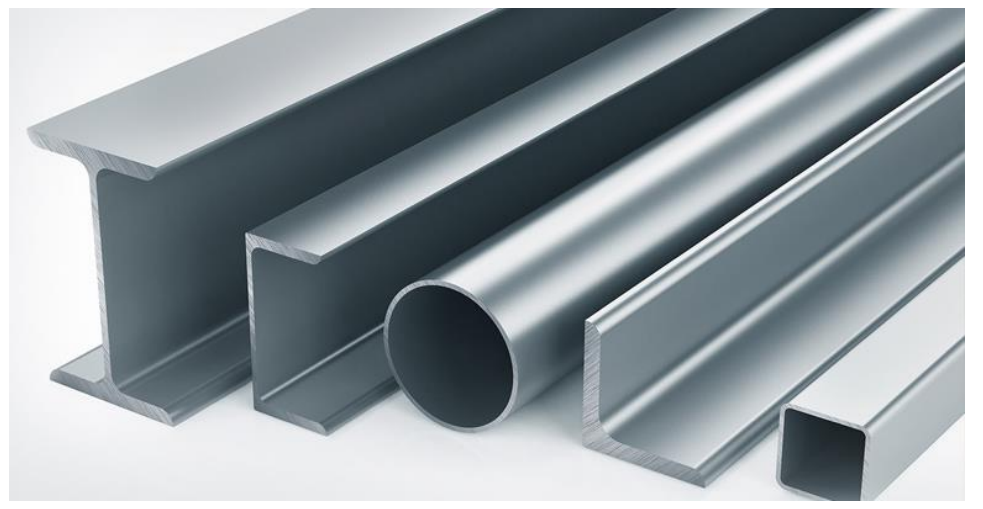

Figure 1. Different shape of aluminum channels [1]

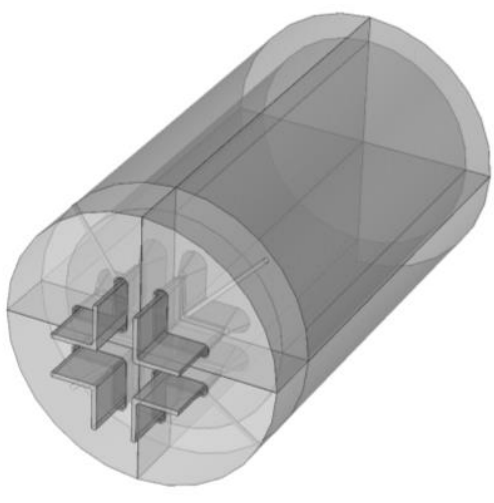

(a) original geometry

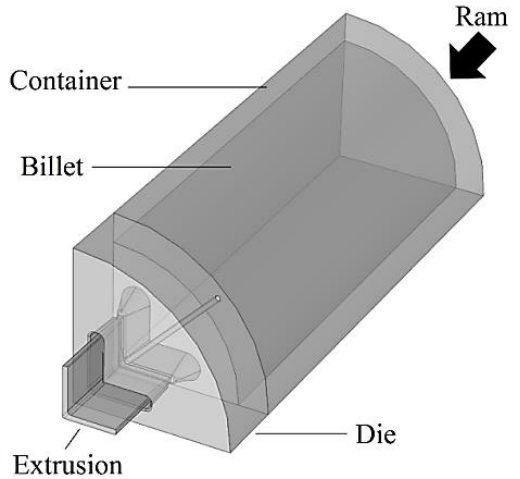

(b) a quarter of the original geometry

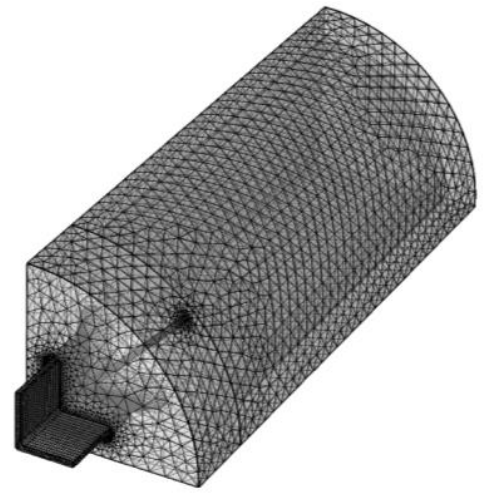

(c) the computational mesh of the domain

Figure 2. Three-dimensional geometry of the aluminium extrusion process 
In large industrial formations processes such as aluminium extrusion, aluminium is deformed through the die in a hot and solid state with the flowing of the aluminium in an ideally plastic condition. Computational fluid dynamics (CFD) simulation can be used effectively to simulate such engineering processes with very high accuracy, where the aluminium material is treated as a fluid that has a very high viscosity which depends on temperature and velocity. When aluminium moving, the inner friction will work as a heat source, therefore the model of the heat transfer is completely coupled together with those governing model of the fluid dynamics. Material properties come into a viscosity function that can be related to the flow stress locally depending on forming velocity and temperature [9-12].

Multiphysics CFD approach for the incompressible Navier-Stokes equations, the solid mechanics equations, and the heat transfer equations have been used to simulate this complex geometrical engineering process. The Navier-Stokes equations for incompressible fluid flow are [13-15],

I. momentum conservation

$$
\rho \frac{d \vec{v}}{d t}=\nabla \sigma
$$

II. total derivative

$$
\frac{d}{d t}=\frac{\partial}{\partial t}+\vec{v} \cdot \nabla
$$

III. incompressibility

$$
\nabla \cdot \vec{v}=0
$$

The stress tensor is defined as [16- 18]

$$
\sigma=2 \eta \dot{\epsilon}-p I
$$

Where, $\eta$ is the viscosity, $\dot{\epsilon}$ is the strain rate tensor, $p$ is the pressure, and $I$ is the identity tensor. The deviatoric stress tensor is defined as $[10,11,16]$,

$$
\begin{gathered}
\tau=\sigma-\frac{1}{3} s p(\sigma) I \\
\tau=\sigma+p I \\
\tau=2 \eta \dot{\epsilon}
\end{gathered}
$$

The equivalent von Mises stress is well-defined in terms of 'the deviatoric stress tensor total contraction' as [10],

$$
\sigma_{e q v}=\sqrt{\frac{3}{2} \tau: \tau}
$$

Using Eq. (7), the equivalent von Mises stress may be rewritten as a function of strain rate as,

$$
\sigma_{e q v}=\sqrt{6 \eta^{2} \dot{\epsilon}: \dot{\epsilon}}
$$

Introducing the equivalent strain rate as $[10,11]$,

$$
\dot{\phi}_{e q v} \equiv \sqrt{\frac{2}{3} \dot{\epsilon}: \dot{\epsilon}}
$$

The equivalent von Mises stress in Eq. (9) can be written as,

$$
\sigma_{e q v}=3 \eta \dot{\phi}_{e q v}
$$

The rate of the strain tensor is calculated as $[10,11]$, 


$$
\dot{\epsilon}=\frac{\nabla v+(\nabla v)^{T}}{2}=\frac{1}{2} \dot{\gamma}
$$

Where, $\dot{\gamma}$ is the shear stress rate, $T$ is the temperature, and $v$ is the velocity.

The shear stress rate $\dot{\gamma}$ is defined as,

$$
\dot{\gamma}=|\dot{\gamma}|=\sqrt{\frac{1}{2} \dot{\gamma}: \dot{\gamma}}
$$

Therefore the equivalent strain rate can be rewritten as,

$$
\emptyset_{e q v}=\frac{1}{\sqrt{3}} \dot{\gamma}
$$

The flow rule states that if the equivalent stress, $\sigma_{e q v}$, in a system amount to the flow stress, $k_{f}\left(\dot{\emptyset}_{\text {eqv }}, T\right)$ then the plastic yielding is occurring.

$$
\sigma_{e q v}=k_{f}
$$

The viscosity is defined as,

$$
\eta=\frac{k_{f}}{3 \phi_{e q v}}
$$

The heat transfer equation is defined as $[19,20]$,

$$
\rho c_{p} \frac{d T}{d t}=\nabla(\lambda \nabla T)+\dot{Q}
$$

Where $\rho$ is the density, $\lambda$ is the thermal conductivity, $c_{p}$ is the heat capacity at constant pressure, and $\dot{\mathrm{Q}}$ is the heat generation rate per volume (heat source) and it is calculated as,

$$
\dot{Q}=f_{v} \sigma: \dot{\epsilon}=f_{v} k_{f} \dot{\phi}_{e q v}
$$

Where, $f_{v}=0.9$. The heat convective from all external surfaces of the system to ambient is governed by,

$$
n .(-\lambda \nabla T)=h\left(T-T_{a m b}\right)
$$

Where, $h$ is the convection coefficient, Tamb is the ambient temperature, and $n$ is the unit vector normal to the surface. The heat radiation from all external surfaces of the system to ambient is governed by,

$$
\text { n. }(-\lambda \nabla T)=\alpha \sigma\left(T^{4}-T_{a m b}^{4}\right)
$$

Where, $\sigma$ is the Stefan-Boltzmann constant and it is equal to $1.38 \mathrm{E}-23[\mathrm{~J} / \mathrm{K}]$, and $\alpha$ is the emissivity.

\section{MODELLING PARAMETERS}

The domain is consisted of two main materials; aluminium for the billet and steel for both of the container and the die. The material properties of the aluminium and steel used in this model are listed in Table 1 [21]. The initial temperatures of the ram are $653 \mathrm{~K}$, the container is $723 \mathrm{~K}$, the billet is $733 \mathrm{~K}$, and die is $677 \mathrm{~K}$. The ambient temperature is $298.15 \mathrm{~K}$. The external temperature of the die and also the ram during the process is set constant at $723 \mathrm{~K}$. The heat transfer coefficient between aluminium (billet) and steel (container and the die) is $11 \mathrm{~N} /(\mathrm{s} \cdot \mathrm{mm} \cdot \mathrm{K})$. The convective heat transfer coefficient with the air outside the system is $15 \mathrm{~W} /\left(\mathrm{m}^{2} \cdot \mathrm{K}\right)$. At the inlet, a steady velocity of $0.5 \mathrm{~mm} / \mathrm{s}$ of the ram moves was applied. At the outlet, a condition of normal stress with zero external pressure was applied. A complete mesh consists of 319994 domain elements, 30365 boundary elements, and 4070 edge elements that have been used in this model. Severe numerical trials were executed to confirm that the solutions of the model remained independent of the grid size. Grid sensitivity has been accomplished to make sure that the solutions acquired using the selected mesh is 
independent of the grid size. An iterative solution for the coupled equations was followed, where an error criterion of $1.0 \times 10^{-6}$ was considered sufficient to achieve the solution convergence. The solution of the calculated variables in the model was measured to be convergent when the comparative error was less than in each field between two consecutive iterations.

Table 1. Material properties

\begin{tabular}{cccccc}
\hline Material & $\begin{array}{c}\text { Density } \\
\rho\left[\mathrm{kg} / \mathrm{m}^{3}\right]\end{array}$ & $\begin{array}{c}\text { Young's modulus } \\
E[\mathrm{GPa}]\end{array}$ & $\begin{array}{c}\text { Heat capacity } \\
c_{p}[\mathrm{~J} / \mathrm{kg} . \mathrm{K}]\end{array}$ & $\begin{array}{c}\text { Thermal conductivity } \\
\lambda[\mathrm{W} / \mathrm{m} . \mathrm{K}]\end{array}$ & $\begin{array}{c}\text { Emissivity } \\
\alpha\end{array}$ \\
\hline Aluminium & 2700 & 70 & 900 & 210 & 0.8 \\
Steel & 7850 & 205 & 475 & 24.33 & 0.8 \\
\hline
\end{tabular}

\section{RESULTS AND DISCUSSION}

Full three-dimensional results during the process of the aluminium extrusion are presented in this section. The present CFD multiphysics simulation model has been validated well with available published experimental results at the same extrusion process conditions listed in reference [3] The exit temperature of the profile of the simulation model has been compared with the measured data provided by Bakhtiani et al. [3], which has before extruded in his experiments, aluminium material through the prefabricated die design (Figure 3). The results of the model validation show that it is less than about $1 \%$ variation in the predicted exit temperature with the measured exit temperature.

The present model has been validated also visually with available previous published data through the comparison of the formation of the dead metal zone of aluminium flow during extrusion as shown in Figure 4. The result shows that the aluminium at the interface between the container and billet moves slower than the aluminium at the centre of the die orifice (slot). This is confirmed by published research [3,17, 18, 22, 23]. The velocity profile during the extrusion process of aluminium will explain the formation of this zone as following result.

Figure 5 shows the velocity profile and the streamline during the extrusion process. The figure shows the suitable design of the system, where all parts of the profile move forward at a similar velocity.

Figures 6 and 7 show the temperature distribution in the system during the extrusion process. The figures show that the temperature increases significantly when aluminium passes through the die slot due to higher friction and deformation. The results give important information that can be used to improve the preliminary die design by modifying the operating conditions.

Figure 8 shows the von Mises stress distribution in the container considering the mechanical load (pressure load) and thermal load (internal friction of the moving material) due to the presence of the fluid. Due to these thermal and mechanical stresses, the total displacement and deformation are introducing in the container during the extrusion process as shown in Figure 9.

Equivalent volumetric strain is a chief parameter in microstructure prediction, especially in grain boundary migration. The equivalent volumetric strain distribution in the container during the process is shown in Figure 10. In general, the higher values of the equivalent volumetric strain appear at the positions of the corners and the edge of the die due to the higher deformation in the billet material. This means in more complex profiles of the dies result in more inhomogeneous strain in the billet. Composed with the effect of friction between the billet and the die land, the deformation of the billet results in an increase in the temperature. The equivalent strain increases considerably once the billet material passes through the die slot where high deformation happens. The figure also clearly shows that the stress distribution in the container effect strains negatively under the impact of temperature increase.

Figures 11 and 12 show the pressure distribution in the billet and the container during the extrusion process respectively. The results show that the pressure distribution in both of the billet and the container is depending on the alloy and its condition. The pressure can vary depending on the shape of the extrudate, the extrusion ratio, the billet diameter and length, the billet initial temperature, and the ram speed. During the extrusion process, energy in the form of dislocations is stored inside the material. The higher degrees of deformation is led to a recrystallised surface area.

The die design in the extrusion process is strongly product dependent. Each die geometry has unique optimum properties such as mechanical properties, extrusion ratio and load requirements. Die design plays a critical part in the extrusion process then it can affect both qualities of the product and productivity. Unsuitable die design can lead to insufficient product specifications and lead to very poor productivity [24]. Many defects can also occur such as distortions, tearing, and pick up. The die design within the poor predictability has led to increased calibration cost and testing. The main aim in aluminium extrusion process is to reach an optimized aluminium flow through the die which results in an exact profile. The visualization of the die during the aluminium extrusion process is shown in Figure 13. The figure shows the distribution of the von Mises stress, equivalent volumetric strain, pressure, and total displacement inside the die. When aluminium reaches the die slot, severe deformation took place. The temperature, strain, stress, and pressure increases significantly when the aluminium passes through the die slot due to the deformation and the friction caused by local stress concentrations. The highest values for all these parameters have occurred on the edge and the corners of the die section where high deformation and friction are taken place. 
Maximum IR temperature $\left[{ }^{\circ} \mathrm{F}\right]$

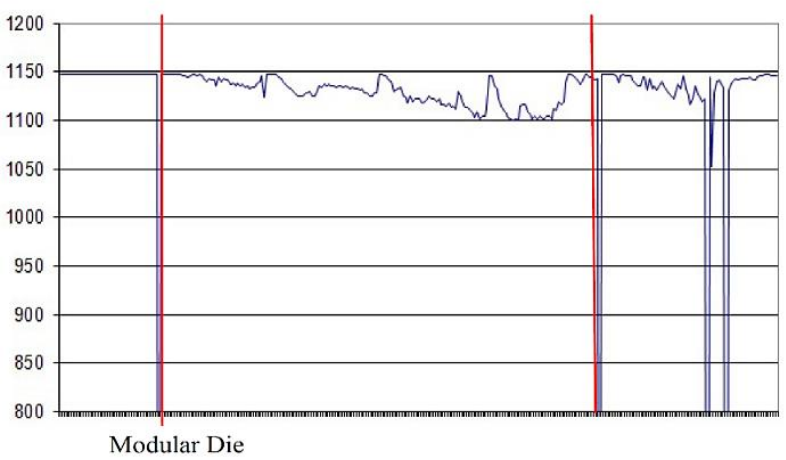

(a) Experimentally measured profile exit temperature [3]

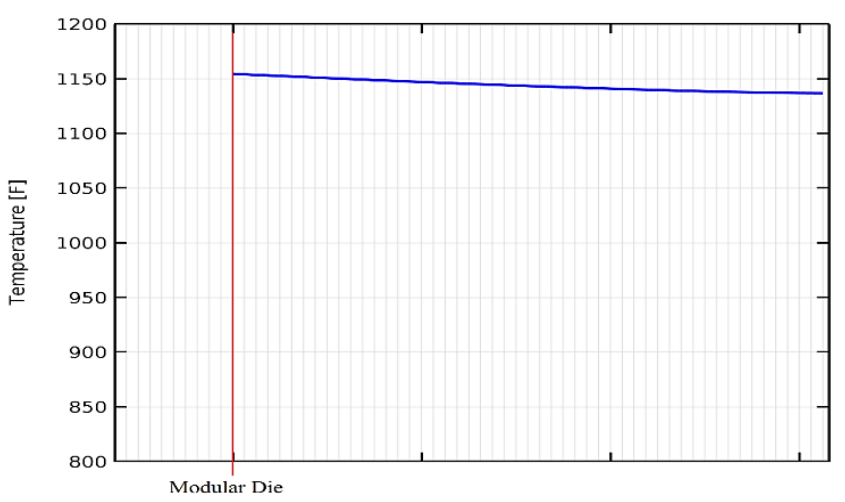

(b) CFD multiphysics simulation model profile exit temperature

Figure 3. The exit temperature of the profile during the process of the aluminium extrusion
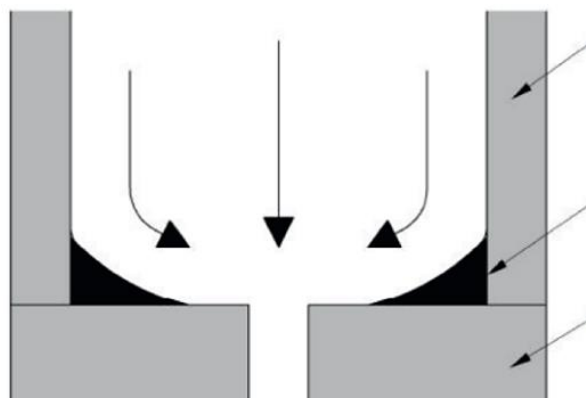

(a) Dead metal zone formation [3]

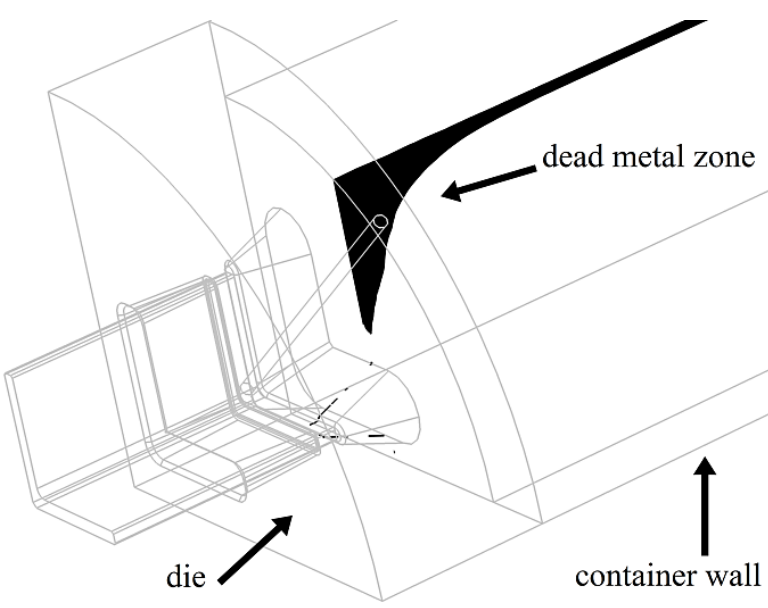

(b) Dead metal zone formation, present CFD multiphysics simulation model

Figure 4. Comparison of the dead metal zone formation with available literature results

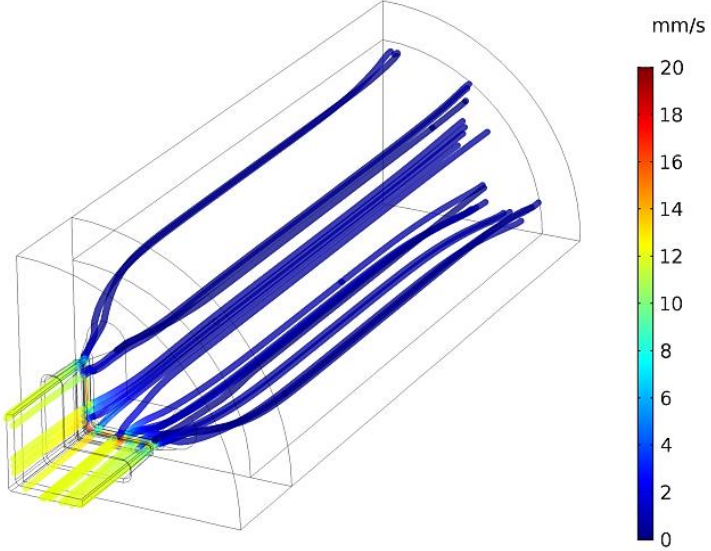

Figure 5. Velocity profile during the process

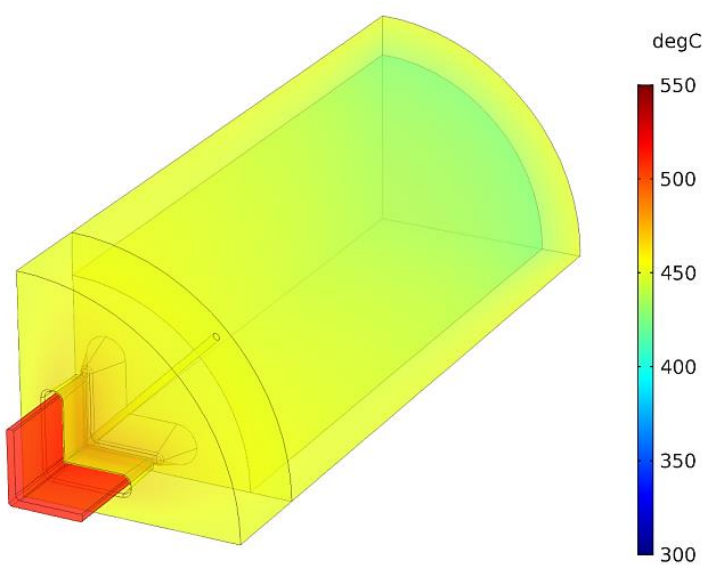

Figure 6. Temperature distribution during the process 


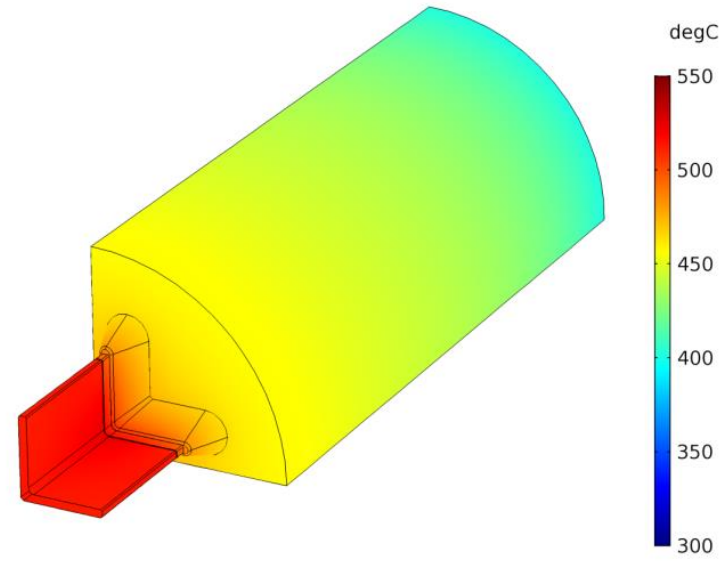

Figure 7. Temperature distribution in the billet during the process

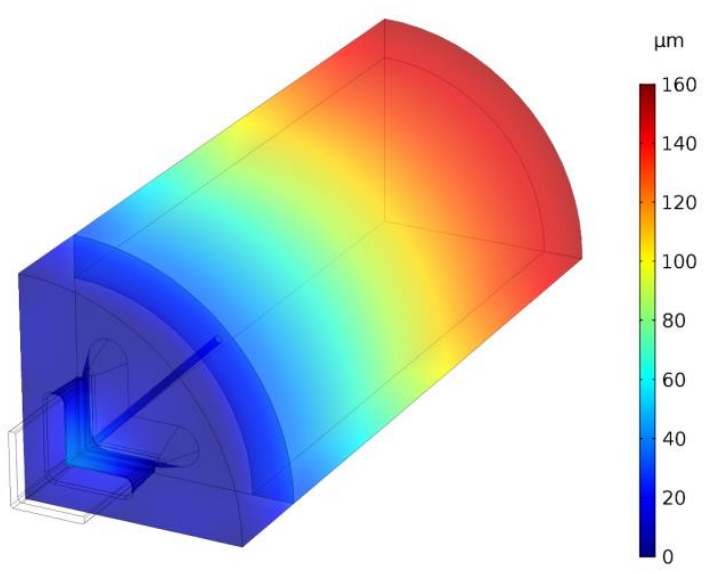

Figure 9. Total displacement distribution in the container during the process

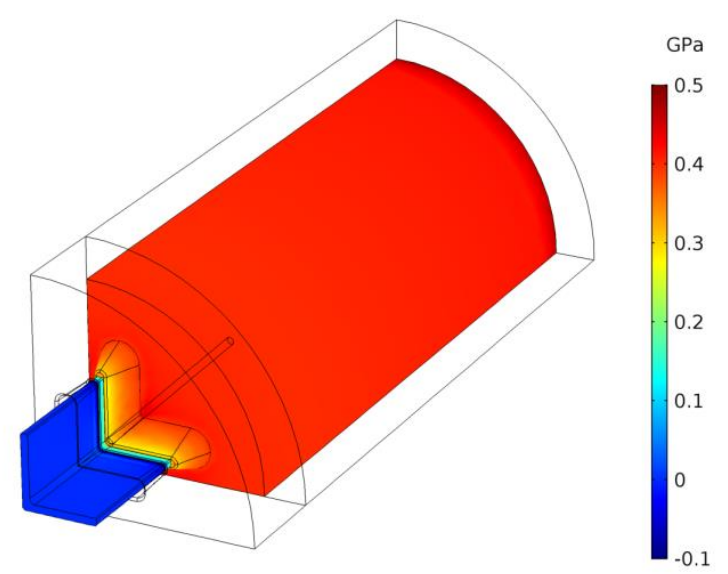

Figure 11. Pressure distribution in the billet during the process

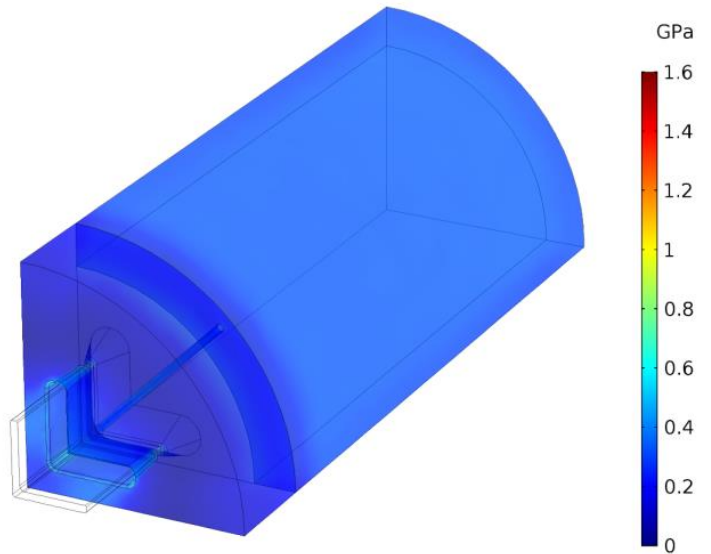

Figure 8. Von Mises stress distribution in the container during the process

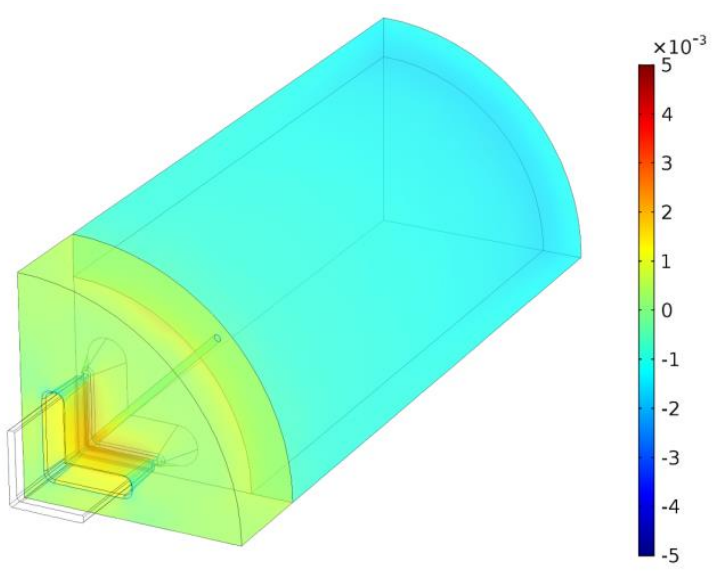

Figure 10. Equivalent volumetric strain distribution in the container during the process

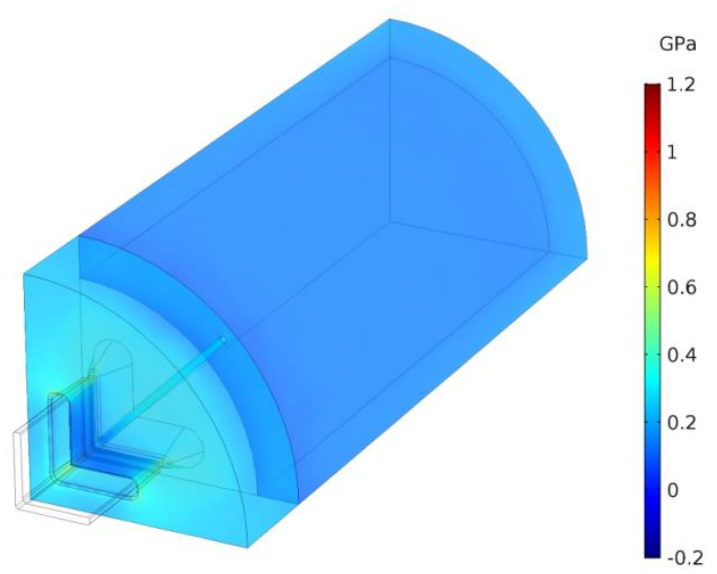

Figure 12. Pressure distribution in the container during the process 


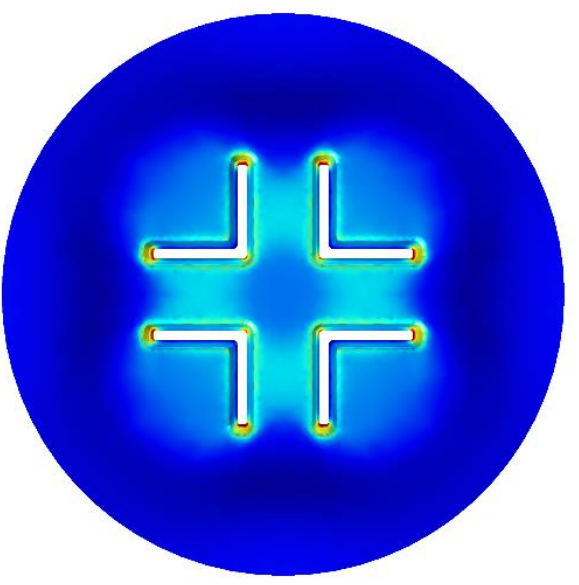

(a) Von Mises stress

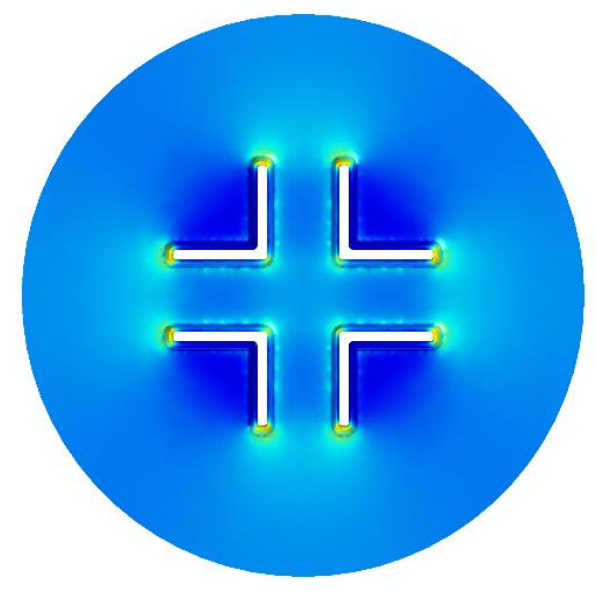

(c) Pressure
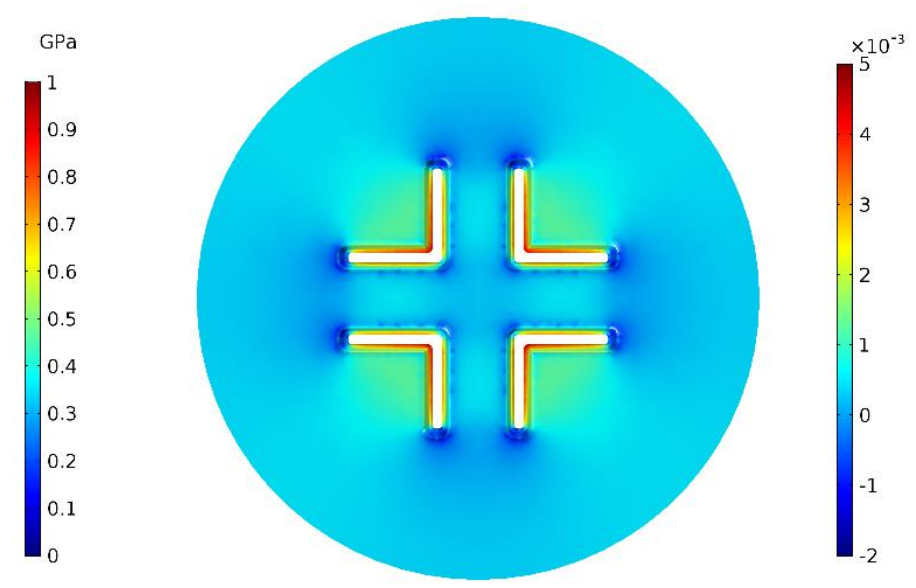

(b) Equivalent volumetric strain

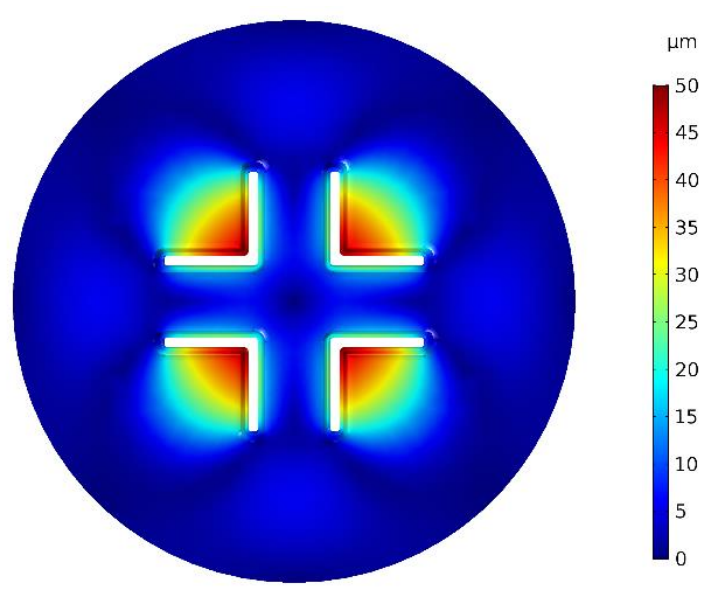

(d) Total displacement

Figure 13. Die visualization during the process

\section{CONCLUSIONS}

Three-dimensional fluid-thermal-structure multiphysics interaction simulation model of aluminium extrusion process has been simulated and presented in this paper. This multiphysics complex geometrical engineering process is simulated effectively using computational fluid dynamics (CFD) simulation with very high accuracy, where the aluminium material is treated as a fluid that has a very high viscosity which depends on temperature and velocity. When aluminium moving, the inner friction will work as a heat source, therefore the model of the heat transfer are completely coupled together with those governing model of the fluid dynamics. Material properties come into a viscosity function that can be related to the flow stress locally depending on forming velocity and temperature. In addition, the thermal and mechanical stress distributed in the die that introduce as a result of the fluid pressures as well as the thermal loads has been modelled by fully coupled the simulation model with the structural mechanics analysis. This work could be extended to consist of further design features in the research study. Furthermore, the present research work could be more extended to study the relationship between die designs and extrusion processing parameters such as; the speed variation of the ram, the temperature setting of the ram, the temperature setting of the billet, and the temperature setting of the container. Further optimisation of design features and extrusion processing parameters are required to develop the applied extrusion process by improving productivity and reducing scrap.

\section{REFERENCES}

[1] K. E. Nilsen, "Numerical modelling of the aluminium extrusion process and comparison with results obtained from industrially extruded complex sections," Ph.D. Thesis, Bournemouth University, 2014.

[2] M. Kulczyk, S. Przybysz, J. Skiba, and W. Pachla, "Severe plastic deformation induced in Al, Al-Si, Ag and Cu by hydrostatic extrusion," Arch. Metall. Mater., vol. 59, no. 1, pp. 59-64, 2014, doi: 10.2478/amm-2014-0010.

[3] T. Bakhtiani, H. El-Mounayri, and J. Zhang, "Numerical simulation of aluminum extrusion using coated die," Mater. Today Proc., vol. 1, no. 1, pp. 94-106, 2014, doi: 10.1016/j.matpr.2014.09.018. 
[4] J. D. Bressan, M. M. Martins, and S. T. Button, "Analysis of aluminium hot extrusion by finite volume method," Mater. Today Proc., vol. 2, no. 10., pp. 4740-4747, 2015, doi: 10.1016/j.matpr.2015.10.007.

[5] A. S. Chahare, and K. H. Inamdar, "Optimization of Aluminium Extrusion Process using Taguchi Method," IOSR J. Mech. Civ. Eng., vol. 17, no. 01, pp. 61-65, 2017, doi: 10.9790/1684-17010016165.

[6] S. Lou, G. Zhao, R. Wang, and X. Wu, "Modeling of aluminum alloy profile extrusion process using finite volume method," J. Mater. Process. Technol., vol. 206, no. 1-3, pp. 481-490, 2008, doi: 10.1016/j.jmatprotec.2007.12.084.

[7] A. Farjad Bastani, T. Aukrust, and S. Brandal, "Optimisation of flow balance and isothermal extrusion of aluminium using finite-element simulations," J. Mater. Process. Technol., vol. 211, no. 4, pp. 650-667, 2011, doi: 10.1016/j.jmatprotec.2010.11.021.

[8] Z. He, H. N. Wang, M. J. Wang, and G. Y. Li, "Simulation of extrusion process of complicated aluminium profile and die trial," Trans. Nonferrous Met. Soc. China (English Ed., vol. 22, no. 7, pp. 1732-1737, 2012, doi: 10.1016/S10036326(11)61380-0.

[9] M. Schikorra, L. Donati, L. Tomesani, and A. E. Tekkaya, "Extrusion Benchmark 2007 - Benchmark Experiments: Study on Material Flow Extrusion of a Flat Die," Key Eng. Mater., vol. 367, pp. 1-8, 2008, doi: 10.4028/www.scientific.net/kem.367.1.

[10] E. D. Schmitter, "Modelling massive forming processes with thermally coupled fluid dynamics," Proc. COMSOL Multiphysics User's Conf., no. 1, pp. 2-4, 2005.

[11] D. B. Alfaro, E. Cueto, M. Doblare, and F. Chinesta, "Three-dimensional simulation of aluminium extrusion by the alphashape based natural element method," Computer Methods in Applied Mechanics and Engineering, vol. 195, no. 33-36, pp. 4269-4286, 2006, doi: 10.1016/j.cma.2005.08.006.

[12] R. A. Neama, M. A. R. S. Al-Baghdadi, and M. Al-Waily, "Effect of blank holder force and punch number on the forming behavior of conventional dies," Int. J. Mech. Mechatronics Eng., vol. 18, no. 4, pp. 56-64, 2018.

[13] M. Al-Waily, M. A. R. S. Al-Baghdadi, and R. H. Al-Khayat, "Flow velocity and crack angle effect on vibration and flow characterization for pipe induce vibration," Int. J. Mech. Mechatronics Eng., vol. 17, no. 5, pp. 19-27, 2017.

[14] R. H. Al-Khayat, M. A. R. S. Al-Baghdadi, R. A. Neama, and M. Al-Waily, "Optimization CFD study of erosion in 3D elbow during transportation of crude oil contaminated with sand particles,” Int. J. Eng. Technol., vol. 7, no. 3, pp. 1420-1428, 2018, doi: 10.14419/ijet.v7i3.14180.

[15] M. A. R. Sadiq Al-Baghdadi, Z. M. H. Noor, A. Zeiny, A. Burns, and D. Wen, "CFD analysis of a nanofluid-based microchannel heat sink," Therm. Sci. Eng. Prog., vol. 20, no. July, p. 100685, 2020, doi: 10.1016/j.tsep.2020.100685.

[16] J. D. Bressan, M. M. Martins, and C. Bandini, "Validation of Finite Volume Method by hot extrusion analysis of aluminium alloy," Mater. Today Proc., vol. 10, pp. 234-241, 2019, doi: 10.1016/j.matpr.2018.10.401.

[17] K. P. V. Namburi, A. F. Kothasiri, and V. S. M. Yerubandi, "Modeling and simulation of Aluminum 1100 alloy in an extrusion process," Mater. Today Proc., vol. 23, pp. 518-522, 2020, doi: 10.1016/j.matpr.2019.05.398.

[18] A. Šupić, A. Bečirović, A. Obućina, and M. Zrilić, "Modeling and Simulation for Aluminium Profile Extrusion," Procedia Struct. Integr., vol. 13, pp. 2077-2082, 2018, doi: 10.1016/j.prostr.2018.12.205.

[19] F. Parvizian, T. Kayser, C. Hortig, and B. Svendsen, "Thermomechanical modeling and simulation of aluminum alloy behavior during extrusion and cooling," J. Mater. Process. Technol., vol. 209, no. 2, pp. 876-883, 2009, doi: 10.1016/j.jmatprotec.2008.02.076.

[20] H. Zhang, X. Li, X. Deng, A. P. Reynolds, and M. A. Sutton, "Numerical simulation of friction extrusion process," J. Mater. Process. Technol., vol. 253, no. November, pp. 17-26, 2018, doi: 10.1016/j.jmatprotec.2017.10.053.

[21] C. P. Kohar, A. Brahme, F. Hekmat, R. K. Mishra, and K. Inal, "A computational mechanics engineering framework for predicting the axial crush response of Aluminum extrusions," Thin-Walled Struct., vol. 140, no. February, pp. 516-532, 2019, doi: 10.1016/j.tws.2019.02.007.

[22] R. Comminal, M. P. Serdeczny, D. B. Pedersen, and J. Spangenberg, "Motion planning and numerical simulation of material deposition at corners in extrusion additive manufacturing," Addit. Manuf., vol. 29, no. December 2018, p. 100753, 2019, doi: 10.1016/j.addma.2019.06.005.

[23] A. Medvedev, A. Bevacqua, A. Molotnikov, R. Axe, and R. Lapovok, "Innovative aluminium extrusion: Increased productivity through simulation," Procedia Manuf., vol. 50, pp. 469-474, 2020, doi: 10.1016/j.promfg.2020.08.085.

[24] S. N. H. Mazlan, A. Z. Abdul Kadir, N. H. A. Ngadiman, and M. R. Alkahari, "Evaluation of geometrical benchmark artifacts containing multiple overhang lengths fabricated using material extrusion technique," J. Mech. Eng. Sci., vol. 14, no. 3, pp. 7296-7308, 2020, doi: 10.15282/jmes.14.3.2020.28.0573. 